\title{
Coal mill explosion-proof monitoring system design and development
}

\author{
Chunxiu Zhang \\ North China Electric Power University, Baoding 071003,China; \\ 1597629272@qq.com
}

Keywords: Coal mill, CO probe sensor, Explosion-proof warning, PLC program control, Software development

\begin{abstract}
Based on the actual operation of the simulation data and adopted PLC program control, it can become an independent system, by sampling, purging, gas sample, sample pretreatment, gas analysis, instrument calibration, program control and the signal output and other parts, and will be assisted with CO probe sensor monitoring analysis, in order to design and development of coal mill explosion-proof monitoring system software.Through the analysis of characteristics of coal mill run, determine the control indicator;Filtering from the simulated data mining and, find out the related data that conforms to the national standard, through the analysis of the concentration of the mill CO, fully considering the coal mill explosion-proof monitoring of the matching relation of between temperature and $\mathrm{CO}$, Puting forward suggestions to adjust to make the actual operating system perfect, the early warning of possible explosion, guiding the staff operation, so as to ensure the safety of the coal mill, and realize the coal-fired power plant, coal yard production process monitoring, an effective means of safe production and environmental protection.
\end{abstract}

\section{Introduction}

The coal mill explosion-proof monitoring system research aimed at the shortcomings of the existing technology, aimed at CO probe sensor as the main tools, and based on the analysis of the concentration of the CO data in real-time monitoring of the coal mill, on the premise of meeting the national standard, the collection of hardware of PLC program control and software of computer language two-way control at a suit, a set of comprehensive consideration of safety, economy and environmental protection evaluation system to guide explosion-proof early warning monitoring system research and design and development to meet the demand of production of the coal mill explosion-proof monitoring system.

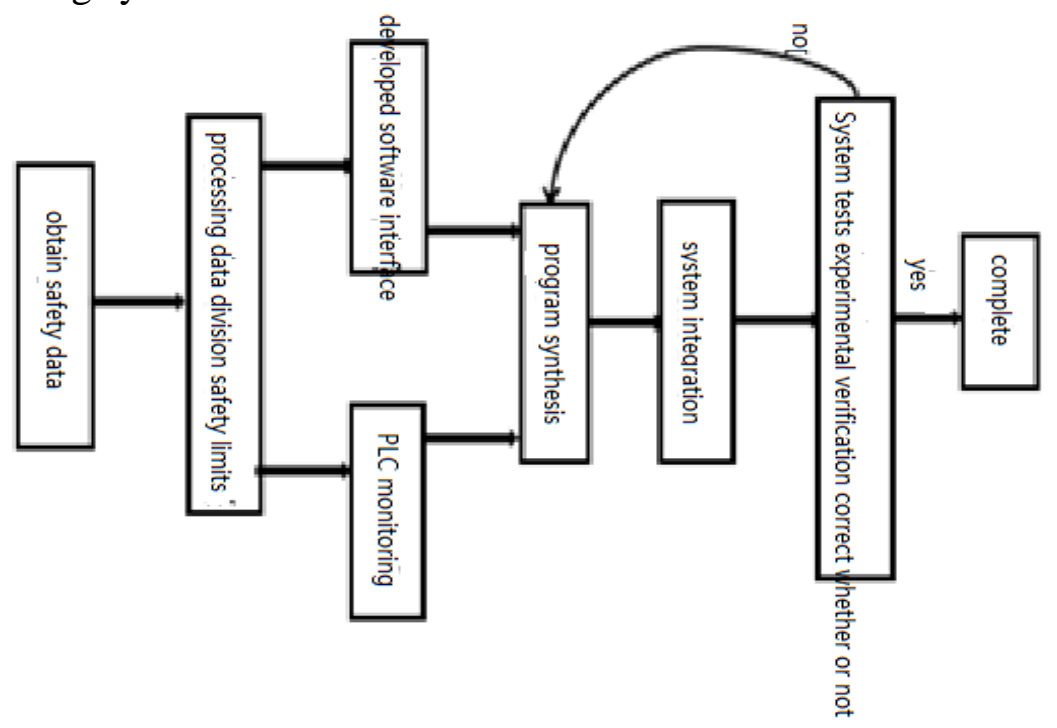




\section{The hardware system}

\subsection{The principle of program control}

This design mainly adopts PLC program control. Specific principle and work process is as follows: the program follows the serial works and I performs an operation every time.

Press the switch sb1, contact 0.01 closure and self-locking, 10.00 closed normally open contacts:

(1)10.01 closed normally open contact, yellow light on;

(2)Reach a level 2 warning, switch closed Sb3 ,contact 0.03 closure and self-locking, 10.02 normally closed contact, yellow light out, red light on, and nitrogen blowback;

(3)Reach a level 3 warning, switch sb4 closed, contact 0.04 closure and self-locking, 10.03 switch normally closed contact, red light out, and close the blowback device, and close all programs.

\subsection{The main functions of the PLC}

First of all, the intelligent monitoring, according to the design can be divided into 3 warning:

(1)When reach a level 1 warning yellow light on;

(2)Reach a level 2 warning yellow light on;

(3)Reach a level 3 warning automatically disconnect main circuit;

So it can achieve the purpose of the intelligent monitoring and early warning.

\section{The software system}

In the coal mill explosion-proof monitoring system, the need for a large number of real-time data acquisition and visual display, after dealing with the software of curve is better than the original data can intuitively impress to the person.

\subsection{System introduction}

The software under the Windows operating system based on c ++ Builder development platform, applied to real-time data in the coal mill explosion-proof monitoring system for the drawing.The $\mathrm{c}+$ + Builder is an tool that faces to object and accomplish easily the visualization of application, development environment is easy and quick, friendly interface, easy to realize.Compatible with mainstream WinXp / 7/8 / Vista operating system. In addition, it uses HTML development with human interface and explains the composition of software and system of principle.The sensor signal after analog-to-digital conversion, you can use the sensor signal data mapping and the operator simply click on starting test after starting software, the software can automatically obtain the actual data, and draw the curve at the same time, visually feedback to the operator.Friendly interface, simply operation.

\subsection{Design structure}

(1)Analysis to get Safety data;

(2) Processing data to divide safety limits;

(3)Developing software interface with PLC monitoring;

(4)Synthetic programs;

(5)System integration;

(6)System testing to investigate whether reasonable;

(7)Complete. 


\subsection{Software running structure}

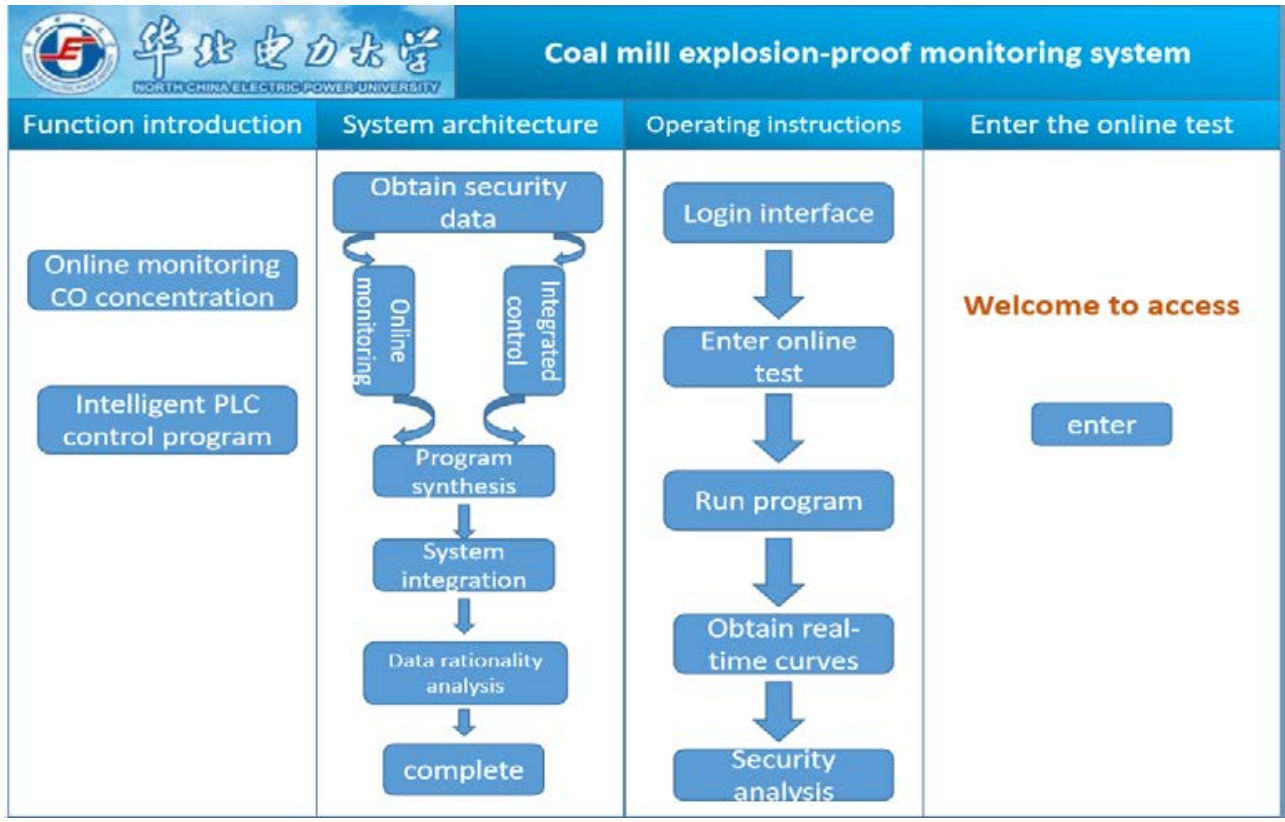

\subsection{Software interface}

Software interface can provide a real time observation data and monitoring and early warning of a human-computer interaction interface.Mainly divided into two parts:

First, the humanized service interface.Users can register, login, and understand the system and the operation principle of coal mill explosion-proof monitoring system;

Second,Visual observation interface. UserS enter data test, a page will show the combustion situation the concentration of CO real-time observation, and security range is marked red line, if beyond the scope of security, it will start early warning device by PLC program and produce corresponding early warning measures or disconnect the circuit.

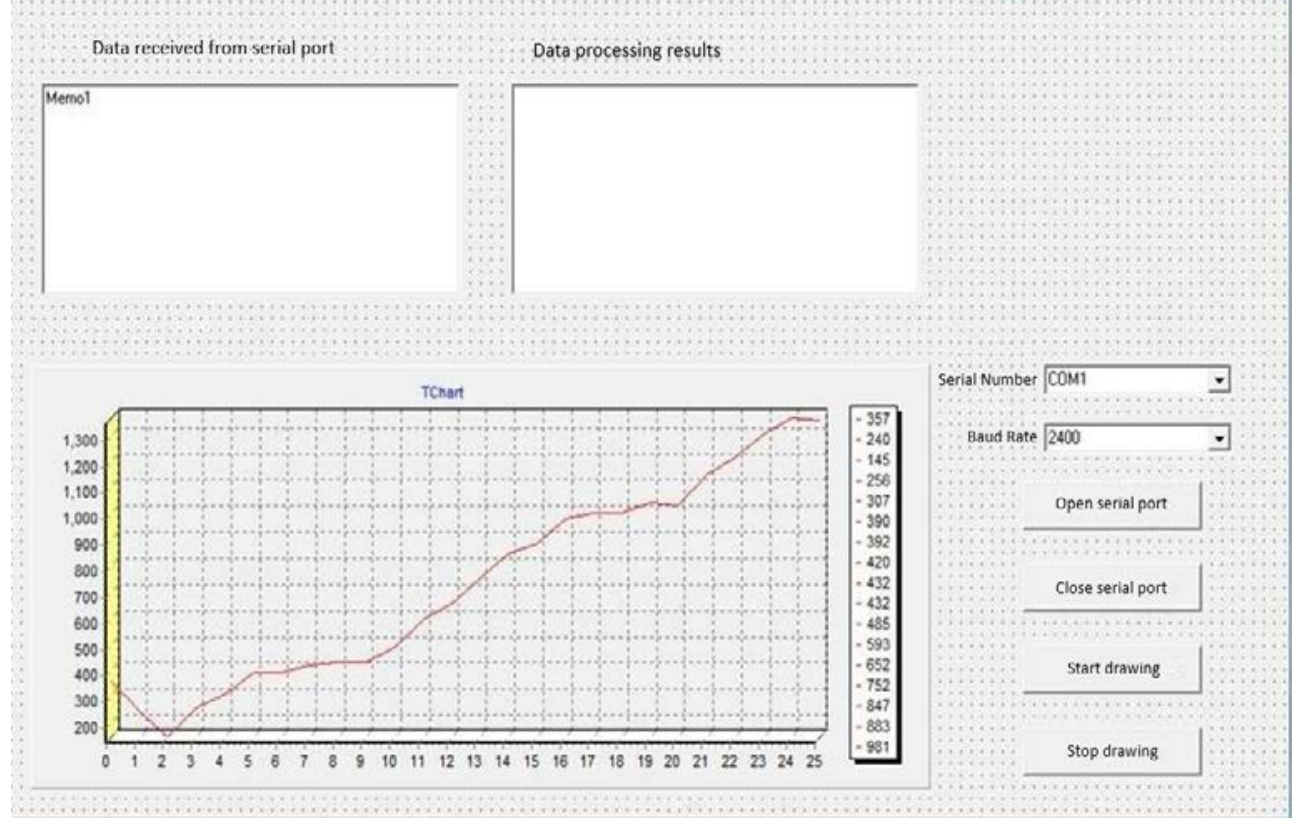

\section{Summary}

The coal mill explosion-proof monitoring system can improve the safety of work and facilitate technology and environmental protection. For the power plant, it can realize the provision of a good coal mill explosion-proof monitoring and early warning system software.With the help of the instruction of sensor and on the basis of a large number of simulation data analysis operation, 
Summarizing the explosion-proof critical index of the early warning, together with hardware and software debugging, providing staff with effective action plan, to improve the operation safety and efficiency of the coal mill group is of great significance.

\section{References}

[1].Haiming zheng, Tieqiao Guo . Coal mill design and application of the early-warning system of fire detection, 2009 (3) : 58-61.

[2] Depu Zou. The causes of pulverized coal pulverizing system explosions study [J]. Journal of northeast electric power technology, 2005 (6) : 38-42.

[3] ZhongyanTang. Mechanical and electrical drive control [M]. Beijing: China power press, 2009:177.

[4]Quan gui Fan etc. Boiler principle [M]. Beijing: China power press, 2008:64.

[5][America]Adobe. Adobe Dreamweaver CS6 Chinese version of the classic tutorial [M]. Beijing: people's posts and telecommunications publishing house

[6]Yong Jiang and so on. $\mathrm{C}++$ Builder6.0 under OpenGL programming techniques [M]. Beijing: electronic industry press 